\title{
Calzone-Like Traumatic Flap Dislocation Four Years after Laser in situ Keratomileusis
}

\author{
Isaak Fischinger ${ }^{a, b} \quad$ Jascha Wendelstein ${ }^{b} \quad$ Matthias Bolz ${ }^{b}$ \\ Manfred Tetz ${ }^{\mathrm{a}}$ \\ aDepartment of Ophthalmology, Augentagesklinik Spreebogen, Berlin, Germany; \\ ${ }^{b}$ Department of Ophthalmology, Johannes Kepler Universität, Kepler Universitätsklinikum, \\ Linz, Austria
}

\section{Keywords}

Cornea $\cdot$ Refractive surgery $\cdot$ LASIK

\begin{abstract}
A 46-year-old patient presented with a flip-folded partially dislocated flap after trauma caused by a sheet of paper, four years after a reportedly uneventful laser in situ keratomileusis procedure using microkeratome. Flap re-lift, mechanical debridement, and flap stretching were performed in a first interventional approach. Due to epithelial ingrowth two month after the first intervention, a flap re-lift and mechanical removal of epithelial cells from the stroma bed and flap were performed. In addition, triamcinolone was applied subconjunctivally. Thereafter, best corrected visual acuity of 20/20 was regained and no more epithelial ingrowth was observed. Only few cases of flap dislocation with epithelial ingrowth have been described in the literature following trauma, though none of a permanently inward folded flap. The use of subconjunctival triamcinolone is a new approach to prevent recurrent epithelial ingrowth.




\section{Introduction}

Since laser in situ keratomileusis (LASIK) was introduced in 1991, it has offered an accurate and safe refractive procedure with fast rehabilitation [1,2] to correct refractive errors. Traumatic flap dislocation is a feared complication, which can occur early, within the first week, or as a late complication up to 14 years after an initially uneventful LASIK procedure [3-6]. Consequences are corneal irregularities, epithelial ingrowth, haze formation, or flap shrinkage [5, 7], which may be associated with decreased visual acuity, glare, and varying levels of discomfort.

We present an unusual case of flap dislocation and a partially "flipped flap" with epithelial ingrowth four years after uneventful LASIK. With two subsequent interventions, the condition was revised and full best corrected visual acuity (BCVA) was restored. Recurrent epithelial ingrowth and haze formation were successfully prevented by the use of subconjunctival triamcinolone.

\section{Case Report}

A 46-year-old man had undergone uneventful LASIK using a microkeratome in 2014 to correct myopia. Apart from that, no other ophthalmic treatments were reported. Four years later, in April 2018, he hit himself with the edge of a sheet of paper in his left eye. At presentation at our clinic four weeks later, the patient reported blurred vision, glare, tears, and pain in his left eye. BCVA was 20/50, and the slitlamp examination of the left eye revealed a partial displacement of the temporal flap margin, which was folded "calzone-like" underneath the central part of the flap (Fig. 1). The bare stroma bed was covered with epithelial tissue, and epithelial ingrowth was present under the folded flap. An average flap thickness of $110 \mu \mathrm{m}$ was measured on the anterior segment optical coherence tomography.

Flap lifting and repositioning was planned under topical anesthesia for the next day. After conjunctival disinfection with povidone-iodine $7.5 \%$ solution (Braunol ${ }^{\circledR}$ ) and topical anesthesia with oxybuprocain (Novesine ${ }^{\circledR} 0.4 \%$ ), the folded flap was lifted with a LASIK spatula and extensively flushed with balanced salt solution. The anterior and posterior side of the flap as well as the stroma bed were properly freed from epithelium by scraping with a hockey knife. Because the flap had slightly shrunken, it was gently stretched mechanically and flushed again with balanced salt solution until a perfect fit was achieved, and the flap was put in its original position. At the end of the procedure, a therapeutic contact lens was applied, and the eye was patched. The patient was instructed to use antibiotic drops (levofloxacine [Oftaquix ${ }^{\circledR}$ ]) and topical dexamethasone (Monodex ${ }^{\circledR}$ ) five times a day for one week. Thereafter, antibiotic drops were stopped, and steroid drops were tapered off gradually over four weeks. Additionally, artificial tears were applied hourly.

Six weeks postoperatively, epithelial ingrowth was detected again at the temporal flap margin which progressed towards the center and caused corneal astigmatism of 2 diopters. A flap re-lift was performed two month after the first intervention, epithelial cells were removed mechanically from the stroma bed and the posterior surface of the flap, and $0.4 \mathrm{~mL}$ triamcinolone acetonide $(40 \mathrm{mg} / 1 \mathrm{~mL})\left(\right.$ Volon $\left.\mathrm{A}^{\circledR}\right)$ were injected subconjunctivally. The patient was informed about the off-label use of the treatment and gave informed consent. Antibiotic and steroid drops were applied in the same way as after the first procedure. One week postoperatively, BCVA was 20/20 and has remained stable since, until the most recent follow-up examination (three months postoperatively). The patient did not complain about any symptoms 
apart from slightly decreased uncorrected distance visual acuity due to mild myopia (SE -1.00 diopter), and the anterior segment examination showed some remaining residual subconjunctival triamcinolone. No flap-related problems were observed (Fig. 2).

\section{Discussion}

Traumatic flap dislocation is an occasionally reported but still rare complication after LASIK, which can occur immediately or many years after surgery $[6,8]$. As there are reports of flap displacements happening up to 14 years [6] and flap re-lifts happening up to 18 years [9] after LASIK, there seems to remain a reduced adhesion of the flap over a long period. Additional corneal crosslinking after LASIK, which demonstrably increases the interface bonding [10], is yet not very popular due to potential side effects [11], extended operating time, and costs. Besides, traumatic flap dislocations are a very rare and unpredictable event, therefore, it remains questionable whether general treatment in all cases is justified to possibly prevent accidental traumatic dislocations. Costs and risks seem to be disproportionally high.

The incidence rate of early flap dislocations is reported as $<0.1 \%$ during the first year and is most often seen within the first few days after surgery [8]. The severity of a dislocation is variable, micro- or macrostriae are reported more often [12]; however, complete flap loss is a rare complication $[9,13]$. To our knowledge, there are no reports of a folded flap case yet, where the flap margin was situated between the central part of the flap and the stroma bed. The folded part of the flap was patched and overgrown by epithelium. That had obviously led to a somehow stable situation, which was tolerated by the patient for a relatively long period (two months). However, some flap shrinkage and epithelial ingrowth had occurred.

Flap dislocation and revision, microkeratome-assisted LASIK, and flap re-lift are known risk factors for epithelial ingrowth $[6,14,15]$, risk factors that were all present in the presented case. In addition, the flap was folded and had shrunken, what might have caused insufficient adhesion to the stroma bed and a gap at the flap margin, allowing epithelial cells to migrate into the interface.

Mitomycin C, ethanol, flap suturing, amnionic membrane graft, fibrin glue, Nd-YAG laser, or phototherapeutic keratectomy are used in addition to mechanical debridement in cases of recurrent epithelial ingrowth [14, 15], but efficacy, costs, and additional effort need to be judged individually. A clinical proof of the efficacy of such a procedure is not available and would be difficult to achieve due to the huge sample size needed for statistical significance. As it is known that topical steroids delay corneal epithelial healing [16], it might appear reasonable that the use of subconjunctival triamcinolone will halt fast epithelial migration into the LASIK interface and prevent epithelial ingrowth. The use of subconjunctival triamcinolone offers an additional reasonable and simple treatment modality for post-LASIK epithelial ingrowth, especially in recurrent cases. In our clinic, triamcinolone is vastly applied for inflammatory conditions of the anterior segment upon informed patient consent to an off-label use. New data suggest positive effects of such a treatment also for the prevention of macular edema [17]. 


\section{Case Reports in Ophthalmology}

\section{Statement of Ethics}

All procedures performed in studies involving human participants were in accordance with the ethical standards of the Institutional Committee and the 1964 Declaration of Helsinki and its later amendments or comparable ethical standards.

The patient gave his written informed consent to publish his case (including publication of images).

\section{Disclosure Statement}

The authors declare no conflicts of interest.

\section{References}

1 Pallikaris IG, Papatzanaki ME, Siganos DS, Tsilimbaris MK. A corneal flap technique for laser in situ keratomileusis. Human studies. Arch Ophthalmol. 1991 Dec;109(12):1699-702.

2 Hersh PS, Brint SF, Maloney RK, Durrie DS, Gordon M, Michelson MA, et al. Photorefractive keratectomy versus laser in situ keratomileusis for moderate to high myopia. A randomized prospective study. Ophthalmology. 1998 Aug;105(8):1512-22.

3 Gimbel HV, Penno EE, van Westenbrugge JA, Ferensowicz M, Furlong MT. Incidence and management of intraoperative and early postoperative complications in 1000 consecutive laser in situ keratomileusis cases. Ophthalmology. 1998 Oct;105(10):1839-47.

$4 \quad$ Lin RT, Maloney RK. Flap complications associated with lamellar refractive surgery. Am J Ophthalmol. 1999 Feb;127(2):129-36.

5 Randleman JB, Shah RD. LASIK interface complications: etiology, management, and outcomes. J Refract Surg. 2012 Aug;28(8):575-86.

6 Holt DG, Sikder S, Mifflin MD. Surgical management of traumatic LASIK flap dislocation with macrostriae and epithelial ingrowth 14 years postoperatively. J Cataract Refract Surg. 2012 Feb;38(2):357-61.

7 Graeff E, Goldblum D. [Outcome of expectant management of epithelial ingrowth in two unequal cases after LASIK]. Klin Monbl Augenheilkd. 2012 Apr;229(4):464-5.

8 Clare G, Moore TC, Grills C, Leccisotti A, Moore JE, Schallhorn S. Early flap displacement after LASIK. Ophthalmology. 2011 Sep;118(9):1760-5.

9 Caster AI. Flap-Lift LASIK 10 or More Years After Primary LASIK. J Refract Surg. 2018 Sep;34(9):604-9.

10 Seiler TG, Engler M, Beck E, Birngruber R, Kochevar IE. Interface bonding with corneal crosslinking (CXL) after LASIK ex vivo. Invest Ophthalmol Vis Sci. 2017 Dec;58(14):6292-8.

11 Seiler TG, Fischinger I, Koller T, Derhartunian V, Seiler T. Superficial corneal crosslinking during laser in situ keratomileusis. J Cataract Refract Surg. 2015 Oct;41(10):2165-70.

12 Moshirfar M, Anderson E, Taylor N, Hsu M. Management of a traumatic flap dislocation seven years after LASIK. Case Rep Ophthalmol Med. 2011;2011:514780.

13 Tetz M, Werner L, Müller M, Dietze U. Late traumatic LASIK flap loss during contact sport. J Cataract Refract Surg. 2007 Jul;33(7):1332-5.

14 Ting DS, Srinivasan S, Danjoux JP. Epithelial ingrowth following laser in situ keratomileusis (LASIK): prevalence, risk factors, management and visual outcomes. BMJ Open Ophthalmol. 2018 Mar;3(1):e000133.

15 Lang SJ, Heinzelmann S, Maier PC, Auw-Hädrich C, Reinhard T. [Epithelial invasion after traumatic flap dislocation]. Klin Monbl Augenheilkd. 2014 Jul;231(7):688-9.

16 Petroutsos G, Guimaraes R, Giraud JP, Pouliquen Y. Corticosteroids and corneal epithelial wound healing. $\mathrm{Br}$ Ophthalmol. 1982 Nov;66(11):705-8.

17 Wielders LH, Schouten JS, Winkens B, van den Biggelaar FJ, Veldhuizen CA, Murta JC, et al.; ESCRS PREMED study group. Randomized controlled European multicenter trial on the prevention of cystoid macular edema after cataract surgery in diabetics: ESCRS PREMED Study Report 2. J Cataract Refract Surg. 2018 Jul;44(7):836-47. 


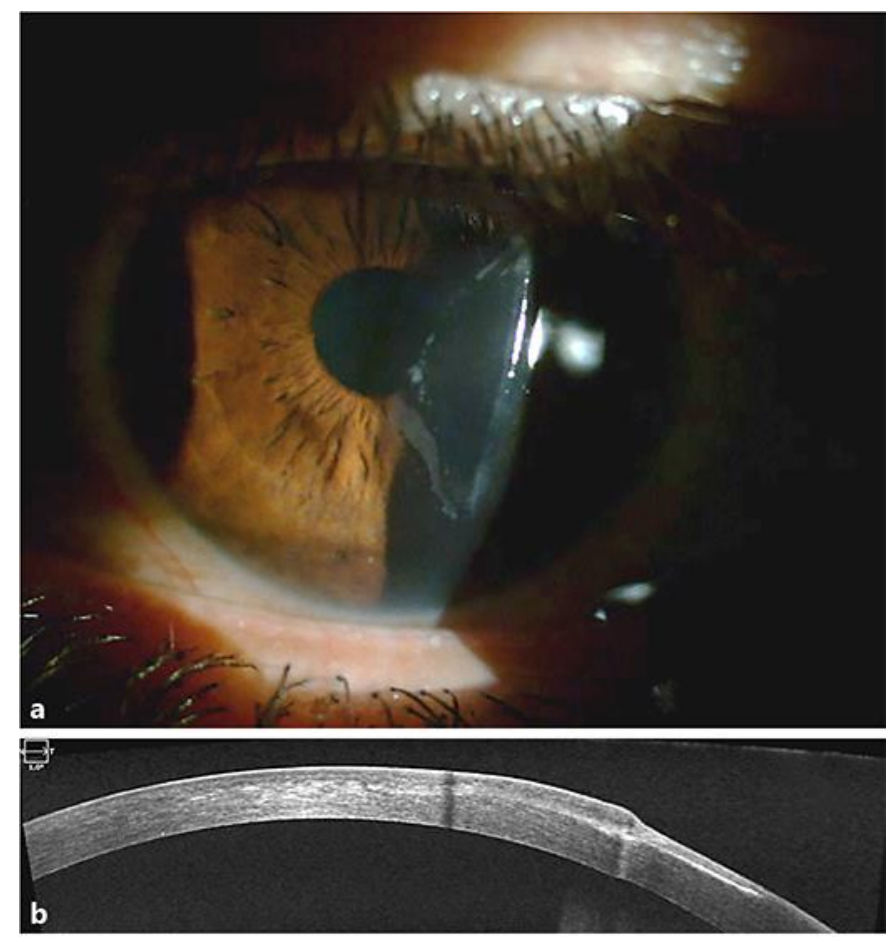

Fig. 1. Preoperative slitlamp (a) and anterior segment optical coherence tomography (b) examination which show a partial displacement of the temporal flap margin, which is folded "calzone-like" underneath the central part of the flap. 


\section{Case Reports in Ophthalmology}

Case Rep Ophthalmol 2019;10:281-286 DOI: $10.1159 / 000502283$ (c) 2019 T www.karger.com/cop

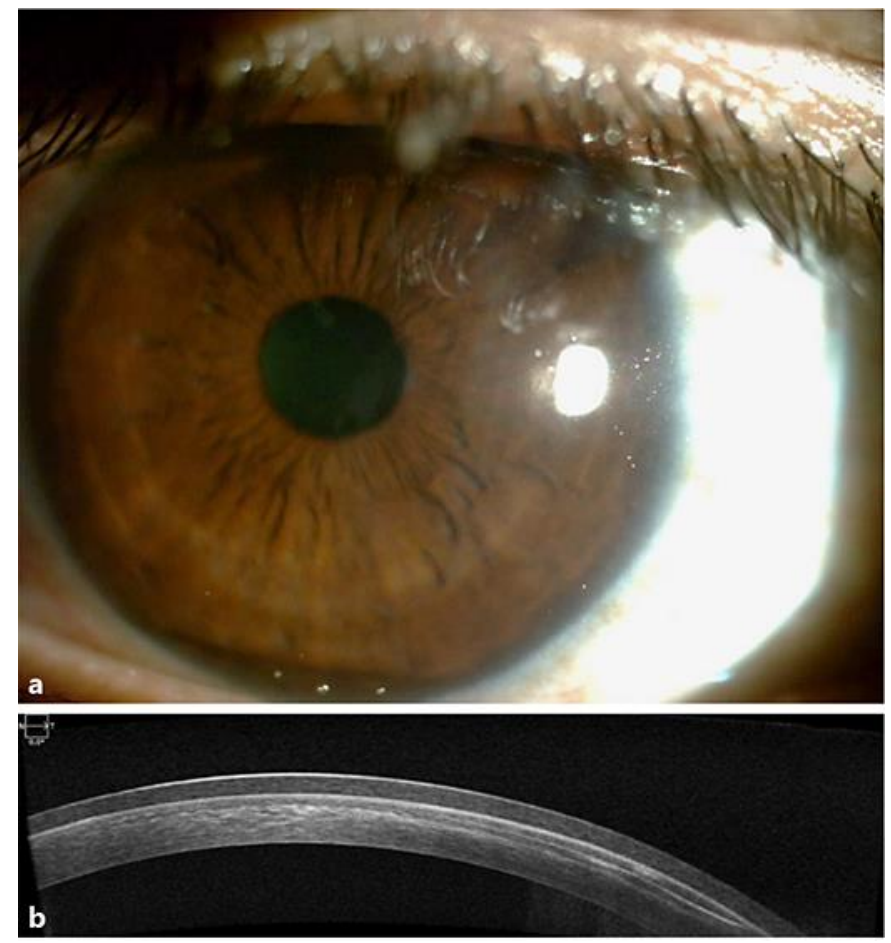

Fig. 2. Slitlamp (a) and anterior segment optical coherence tomography (b) examination three months postoperatively. 